\title{
DA MULHER QUE DEVIEMOS ÀQUELAS QUE HÃO DE VIR: COMO RECONTAR A HISTÓRIA SUSCITA DEVIR
}

\author{
DE LA FEMME QU'ON EST DEVENUE AUX CELLES QU'IL FAUT \\ DEVENIR: RACONTER L'HISTOIRE ET DÉCLENCHER DEVENIRS
}

Carolina Sarzeda ${ }^{1}$

Resumo: O presente trabalho desenvolveu-se partindo de uma pesquisa monográfica a respeito do livro Calibã e a bruxa, de Federici, e a crítica que o mesmo endereça a Foucault. A partir dos três eixos do livro (mulheres, corpo e acumulação primitiva), a história das mulheres aparece em encruzilhada entre as tecnologias de disciplinamento do corpo e de acumulação de capital. Se a tese de Federici é que a história das mulheres é matricial na gênese do capitalismo, e se pretendemos desdobrar do livro estratégias políticas, chegamos aos limites da proposição: qual a relação entre história e devir para as mulheres? A questão é remontada aqui a partir de uma coincidência terminológica: o devenir femme em Beauvoir e o devenir-femme em Deleuze e Guattari. Atravessamos leituras da dupla francesa indicando que, guardadas devidas distâncias conceituais, é possível aproximar o uso que faz Federici da história a uma estratégia de desencadeamento de devires.

Palavras-chave: Caça às bruxas; história das mulheres; devir-mulher.

Resumé: Ce travail est développé à partir de la recherche monographique à propos du livre Caliban et la sorcière, de Federici, et la critique qu'il adresse à Foucault. En partant des trois axes du livre (femmes, corps, accumulation primitive), l'histoire des femmes apparaît au carrefour entre les technologies de disciplination du corps et d'accumulation de capital. Si la thesis chez Federici affirme l'histoire des femmes en tant que matrice à la genèse du capitalisme, et si l'enjeu dont on part est notamment politique, on est devant les limites de la proposition: quelle est la relation entre histoire et devenir pour les femmes? L'enquête est tracée ici à partir de la coïncidence terminologique: le devenir femme chez Beauvoir et le devenir-femme chez Deleuze et Guattari. On traverse les écrits du duo français et indique que c'est possible approcher l'outil historique, tel comme il est utilisé par Federici, aux stratégies déclenchants des devenirs.

Mots-clés: Chasse aux sorcières; histoire des femmes; devenir-femme.

\section{Uma estranha flexão do verbo}

Da mulher que deviemos, àquelas que hão de vir: como recontar a história suscita devir. À primeira versão deste trabalho, apresentado oralmente, dei este nome ${ }^{2}$. E, bem, é preciso que confesse ainda não estar convencida do título. Porque há de se admitir: temos aí uma estranha flexão do verbo. Conjugar "devir" no pretérito estranha e nos deixa a suspeita de que o verbo "devir" não tenha, tecnicamente, um passado. E inculcam logo outras suspeitas, filhas destas

\footnotetext{
${ }^{1}$ Psicóloga formada na Universidade Federal Fluminense (2019). E-mail: carolinasarzeda@gmail.com.

${ }^{2} \mathrm{O}$ trabalho que aqui apresentamos foi originalmente escrito em ocasião do VIII Seminário Conexões que teve lugar na UNICAMP em 2019. Assim, tanto o ritmo do texto quanto a complexidade das ideias estão comprometidos com uma exposição oral do tema. O problema discutido a seguir surge em desdobramento de nosso trabalho de conclusão de curso em Psicologia na UFF e cujo título foi o entusiasmado: Caça contra os corpos rebeldes: Federici e Foucault entre bruxas (2019). Ocasião na qual a leitura do livro de Federici encontrou-se com uma formação universitária afeita aos conceitos foucaultianos, um país em pleno caos e o presente berrando a necessidade de traçarmos novas estratégias de re-existência.
} 
primeiras: estranha flexão do verbo, mas também estranha flexão do gesto. É claro que já temos em mente o conceito de devir - e o verbo no infinitivo - que aparece em Deleuze e Guattari. E é também na leitura do conceito que a flexão do devir ao passado nos alardeia.

Na edição brasileira dos mil platôs, os editores já anunciam antes de deixar-nos a sós com os franceses: devenir - verbo cuja tradução pode empregar, no português, o habitual "tornar" , será lido pelas diversas variações do verbo "devir". A opção se justifica sobretudo a propósito do teor conceitual e técnico que o termo assume repetidamente em Deleuze e Guattari (2012a, p. 7). Embora de acordo com a leitura proposta, lembrar da tradução vulgar de devenir instaura uma dúvida. Há pelo menos dois sentidos de devenir - vamos logo passar ao que interessa - o da mulher de Beauvoir que como tal não se nasce, mas torna-se historicamente, devém-se ${ }^{3}$; e, por outro lado, o da mulher molecular, que se empresta a Deleuze e Guattari, para que seja possível dizer de um outro sentido político de devir - aliás oposto a este que é descrito primeiro por Beauvoir. Assim, a tradução usual de Beauvoir nos remete a um processo histórico de que é preciso dar-se conta. Não se nasce mulher: não há natureza biológica na categoria. Sua gênese, ao contrário, é encontrada na história dos homens e emulada pela cultura na história de cada uma das mulheres. E o que a formulação de Beauvoir inaugura (embora precedida pelas pesquisas freudianas sobre a sexualidade) é um sentido histórico, uma mulher contingencial aos marcos culturais e determinada pelo gênero. Esse sentido é prolongado pelos movimentos escritos e militantes - feministas. Conhecer o que nós fomos historicamente se torna, a partir de então, imprescindível para pensarmos gênero ${ }^{4}$. E tal como vemos, brilhantemente feito por exemplo por Federici, investigar a história também se revela uma tarefa de reconhecer o que persiste estruturando o presente. Há, na autora, uma afirmação de que não é possível ainda se desvencilhar da categoria "mulher" para analisar o capitalismo: não basta conjurar a "mulher" que emularam em nós, é preciso operar a partir disso. Isso nos fará revisitar a história com olhares mais interessados nas mulheres de outros tempos, buscando modos de ser mulher. E não seria difícil imaginar que cheguemos ao final de Calibã e a bruxa reconhecendo essa história de caça às mulheres rebeldes em nós mesmas e reconhecendo estarmos cercadas por uma realidade misógina que não dista tanto assim de uma caçada. É irresistível que saiamos dessa leitura imbuídas da tarefa de demonstrar que os empreendimentos da caça às mulheres

\footnotetext{
${ }^{3}$ A formulação é encontrada em $O$ segundo sexo, mas ecoada como slogan feminista. "On ne naît pas femme, on le devient": não se nasce mulher, torna-se (BEAUVOIR, 1949). Descoberta que, aliás, as investigações freudianas já acusavam a pertinência. Segundo Maria Rita Kehl, a fórmula atribuída à Beauvoir é, na verdade, dita primeiro por Freud ao referir-se ao árduo processo de identificação da menina a seu sexo biológico (KEHL, 2018).

${ }^{4}$ Seria necessário fazer aqui a consideração de que o recorte de nosso trabalho - esse que localiza Silvia Federici logo ao lado da colocação de Beauvoir - não é tão justa. A crítica feminista passou, desde a publicação de $O$ segundo sexo e antes de $O$ calibã e a bruxa, por algumas importantes formulações a respeito do tema e de seus problemas. É importante para aqui localizar a obra de Judith Butler nessa história. Problemas de Gênero (BUTLER, 2003 [1990]) é, então, um livro que responde a alguns problemas de $O$ segundo sexo a respeito da constituição do sujeito feminino, ao passo que continua a partir da deixa de Foucault em $A$ vontade de saber (FOUCAULT, 2017 [1976]). A tese de Butler infere problemas importantes ao feminismo e ao sujeito em torno do qual este se formula. Seria preciso fazer mais do que as feministas haviam feito até ali: centrar-se na categoria mulher e proliferar seus predicados (mulher negra, mulher deficiente, mulher latina, mulher lésbica, mulher trans...) ainda faria um feminismo que lê as diferenças simplesmente por diferentes formas de "ser mulher", o que, em última instância, revolve o feminismo à relação binária com o homem. Poderíamos preliminarmente apontar Angela Davis como teórica desse outro esforço: tomar o predicado por matriz, sem a qual o feminismo não poderia operar. Em seu caso, tomar raça apenas como "marcador" do gênero não será suficiente, será preciso re-equacionar o gênero a partir da raça. Bem, nos parece importante sublinhar, sobretudo, a resposta de Butler à herança feminista porque parece ser em tréplica à autora que Silvia Federici afirma não podermos ainda prescindir da categoria "mulher" para analisar o capitalismo. Vale aqui a lembrança de que, embora aparentemente distante conceitualmente das bruxas, um boneco com o rosto de Judith Butler foi queimado em uma das manifestações contra sua vinda ao Brasil, em novembro de 2017, em meio a gritos de "queimem a bruxa".
} 
persistem muito bem estruturados no presente e que a "mulher" é ainda a mesma e que os homens são ainda os mesmos e que o patriarcado é ainda opressor. $\mathrm{O}$ par dessa mulher que permanece a mesma ao longo da história é o patriarcado que persiste a oprimindo em uma mesma função. Mas afirmando esta história da mulher, corremos o risco de nos contentarmos com a função de reconhecimento das estruturas e nos esquecermos, afinal, que o que nos interessa é justamente o que se passa aquém e além delas. Se a história que produz a mulher limita o que ela pode vir a ser, há na história, como ferramenta, um limite. Qual é a utilidade de se conhecer a história das mulheres? nos perguntaria uma feminista nietzschiana.

Por outro lado, se o devenir femme de Beauvoir toma esse sentido histórico, o devenir-femme de Deleuze e Guattari parece situar-se em oposição. O devir-mulher só aparece a partir de uma distinção entre uma mulher molar e uma outra molecular. O conceito, então, parece ser todo levado por esta última: a mulher do devir minoritário não é a mulher histórica, mas uma região de circulação de diferenças, uma zona onde já não se estaria mais identificada à figura da mulher molar. Um sentido de devenir que, vamos achar na letra, se define em contraste à história. Um devir no infinitivo, não conjugado em tempo verbal ou pronome pessoal. O devir é a-histórico, um puro processo. Do devir, a história é quase seu negativo, o conjunto de condições e o registro do acontecimento apenas em seu estado de coisa. (DELEUZE, 2013, p. 214). Mas então o primeiro ruído: qual a relação entre a história da mulher molar que deviemos e o devir-mulher molecular? Se, por um lado, devir não é história, por outro, qual é a relação entre os dois termos?

\title{
Um ruído na história
}

\author{
The witch was the communist and terrorist of her \\ time, which required a 'civilizing'drive to produce \\ the new 'subjectivity' and sexual division of labor on \\ which the capitalist work discipline would rely
}

FEDERICI, 2018. p. 33.

Em meu trabalho de conclusão de curso - é preciso, agora, mais este preâmbulo - tomei o livro de Silvia Federici, no intuito de mapear a crítica a Foucault presente no livro. Calibã e a bruxa: mulheres, corpo e acumulação primitiva escreve a história da formação do mundo capitalista encarando um esquecimento sintomático das historiografias: toma como ponto de partida a caça às bruxas. Um processo que condenou e assassinou centenas de milhares de mulheres no lapso de aproximadamente três séculos da história da Europa ocidental - bem como o fez no "além-mar", em agenciamento com a colonização. A história deste extermínio é usualmente contada tal como se tratasse de uma poesia folclórica, um conto infantil. Tal como se as fogueiras que queimaram as bruxas tivessem sido ateadas por seres fantásticos e que a carne incendiada não ardesse.

No entanto, entre a "transição" para o capitalismo e a opressão contra as mulheres há mais parentesco do que se poderia supor. Foi imprescindível a produção de uma "mulher" para que o capitalismo se desdobrasse. Por isso mesmo, reler o capitalismo a partir de seus bastidores invisíveis, como se propõe Federici, recoloca inteiramente seu processo de formação: páginas que recifram a história para decifrá-la novamente. Federici enxerta a história das mulheres na história do capitalismo. Se ainda não o fizemos, o faremos: ler histórias de mulheres e fazer ler a partir de histórias das mulheres. Pois então que descobrimos haver, em história e corpo das mulheres, segredos infames sobre história e corpo do capitalismo: a produção de uma "mulher" é a produção de uma máquina de reprodução de força de trabalho. E a caça às bruxas demonstra que foi necessário empreender uma luta contra as mulheres rebeldes em favor da construção da "mulher", máquina de reprodução, para que os fluxos do capital fossem garantidos. 


\section{Mulheres, corpo e acumulação primitiva}

Aparentemente, se supomos óbvia a já dita distinção entre história e devir, o que escreve Federici em seu livro parece se tratar, sem tanta dúvida, de uma discussão meramente histórica. Ainda porque a autora expressamente aponta a opção por insistir não só na história das mulheres, mas também no uso de "mulheres" enquanto categoria de análise histórica e política. Parece que sua introdução, ao marcar em alta voz suas críticas contra Foucault e Marx, estaria mais no sentido de uma política molar das mulheres. Pois, ora, vejam: se em Mil platôs as mulheres levam a cabo uma política molar quando dizem "nós, enquanto mulheres..." - em função de uma operação de conquista do próprio organismo, de sua própria história, de sua própria subjetividade (DELEUZE; GUATTARI, 2012b, p. 71), com Calibã e a Bruxa todas nós dissemos: a história das mulheres é a história das classes (FEDERICI, 2017, p. 31); o que Foucault teria aprendido (ibid., p. 36), o que Marx teria sabido, tivessem ambos analisado a história das mulheres. Devir mulher, nas fileiras feministas desde Beauvoir e sem hífen, é molar; devir-mulher, de Guattari e Deleuze e acuso o hífen ${ }^{5}$, molecular - seria, assim, simples? Pois que ainda sem saber articular esta questão, nas últimas páginas da referida e entusiasmada monografia, o devir aparece. Assim: como palavra, nem tanto o conceito, um devir é suscitado. Daí o interesse de hoje em traçar o caminho inverso para pensar como um trabalho que passou a todo tempo por fazer história das mulheres suscita, ao final, um devir. Mas não vem bem da dupla de franceses que: “(...) escrever não têm talvez outro objetivo: desencadear devires" (DELEUZE; GUATTARI, 2012b, p. 66)?

Ainda que, de aliança, tenha o recurso historiográfico, a forma com que a autora ítaloestadunidense trata de fazer esta história não é tão óbvia. Calibã e a Bruxa monta uma tríptica conceitual que lhe serve de importante dispositivo. Mulheres; corpo; e acumulação primitiva: é o que subtitula a obra, reparando nas três referências teórico-práticas da condução dessa pesquisa. Mas não só isso. Apontam também, e grifemos bem, para uma operação. Opera-se assim um trançar, um transar, um transitar. De modo que um termo coloca um limite imanente ao termo anterior; de modo que um termo é a justa medida do anterior e o que o sucede é a medida também destes dois. As três vias críticas, a tríptica conceitual acaba por funcionar como um limite que devolve/revolve um primeiro termo aos outros dois: a história da caça às bruxas só se faz nessa tríptica operação, que impede que qualquer um deles se totalize. Pois há sempre um terceiro termo, há sempre um ruído - que desvia, excede, perverte, enfeitiça. Portanto, impossível percorrer qualquer um dos temas sem sofrer os efeitos nevrálgicos daquilo que o excede, precisamente porque é nesse emaranhado de corpos, histórias, mulheres, sangue e fogo que esta história se faz.

\section{Devir e a Bruxa}

Dizem Deleuze e Guattari:

Devir é, a partir das formas que se tem, do sujeito que se é, dos órgãos que se possui ou das funções que se preenche, extrair partículas, entre as quais instauramos relações de movimento e repouso, de velocidade e lentidão, as mais próximas daquilo que estamos em vias de devir, e através das quais devimos (2012b, p. 67).

O que seriam estas "formas que se tem" senão as histórias de nossos corpos?, e neste caso insistiria: quais as formas a partir das quais se devém-mulher - com hífen - senão as formas da

\footnotetext{
${ }^{5}$ Liane Mozère, em um artigo sobre o devenir-femme, explicita o hífen no conceito deleuzo-guattariano. No devirmulher, dirá, o que é primeiro é todo o conjunto formado por hífen, infinitivo e substantivo (MOZÈRE, 2005).
} 
mulher que deviemos, ora, historicamente - sem hífen? Ainda: de onde extrair as tais partículas, como instaurar as tais relações? Devir, mas não é também preciso decifrar através do quê? Gostaria então de propor a estas questões um adensamento, um corte cola, pra que leiamos devir junto das mulheres - nós aqui presentes, as bruxas e, claro, Federici.

A partir do que dizem Guattari e Deleuze neste mesmo platô (ibid., p. 71), empregamos um "nós" que nos convenha para reler o que os autores escrevem. E leremos: a mulher que nós deviemos historicamente tem que devir-mulher, para que o homem, só então, devenha. Ou possa devir. É certamente indispensável que "nós, enquanto mulheres," operemos uma conquista de nosso próprio organismo, de nossa própria história, de nossa própria subjetividade. Se devir e história são distintos, não são, no entanto, separados. E, pois, que este enxerto (o da mulher na história) opera uma amputação. O que se subtrai quando entram as mulheres?

Haveria, então, dois sentidos da história feita por Federici. Se por um lado, as palavras de ordem gritam algumas sentenças de morte e as mulheres são invocadas enquanto categoria, as bruxas enquanto história, os acontecimentos enquanto fatos, fazer esta história de criação da mulher molar nos permite perceber quais as constantes subtrair; e aprendemos com o platô do $\mathrm{CsO}$ a instalarmo-nos sobre a mulher molar, a mulher que deviemos historicamente, experimentarmos as oportunidades que ela nos oferece, buscar aí um lugar favorável, eventuais movimentos de desterritorialização, linhas de fuga possíveis e vivenciá-las, ter sempre um pequeno pedaço de uma nova terra (DELEUZE; GUATTARI, 2012a, p. 27). Mas no sentido da criação das mulheres moleculares, que escolho nomear aqui enquanto feministas. Mas poderia chamar de qualquer um dos múltiplos nomes que a História deu aos nossos desvios. O perigo é acreditar demais nesta História, o perigo é parar de desviar, achando que já encontramos a fonte primeira e o nome último a nos dar. Ora, contra este perigo, estão as diferenças, os dissensos: que não param de fazer nascer novos pontos de partida dos quais contamos novas histórias. Se existem senhas sob as palavras de ordem, palavras como que passagens, componentes de passagem, há bruxas por baixo de toda mulher, pois a questão não era: como escapar à mulher?, mas como escapar à sentença de morte que ela envolve. A mesma coisa, a mesma mulher, "tem sem dúvida essa dupla natureza: é preciso extrair uma da outra - transformar as composições de ordem em componentes de passagem." (DELEUZE; GUATTARI, 2011, p. 62). É preciso, portanto, conceber uma política que parta da mulher e a ultrapasse, que tanto se insinue nos afrontamentos molares, quanto passe por baixo, ou através deles (DELEUZE; GUATTARI, 2012b p. 72). Isto, diria Federici, se trata, pois, de uma verdadeira "operação da categoria mulher enquanto ferramenta de análise do capitalismo" (FEDERICI, 2017, p. 23).

"A questão é primeiro a do corpo" - diz Deleuze ao lado de Guattari - "o corpo que nos roubam para fabricar organismos oponíveis". (DELEUZE; GUATTARI, 2012b, p. 72) E Silvia, por sua vez diria: antes do relógio e da máquina a vapor: o corpo foi a primeira máquina criada por e para a produção capitalista. (FEDERICI, 2017, p. 268) "O desenvolvimento da 'máquina humana' foi o principal salto tecnológico, o passo mais importante no desenvolvimento das forças produtivas que teve lugar no período de acumulação primitiva." (ibid., p. 267) Transforma-se um "Corpo como meio de produção, [como] máquina de trabalho primária" (ibid., p. 247). "E, ora" - retomam os franceses - "é à menina, primeiro, que se rouba esse corpo. (...) É à menina, primeiro, que se rouba seu devir para impor-lhe uma história, ou uma pré-história." (DELEUZE; GUATTARI, 2012b, p. 72) Ao que devemos, de novo com Federici, reivindicar: "A conquista do corpo feminino continua sendo uma precondição para a acumulação de trabalho e de riquezas." (ibid., p. 36) A colonização sangrenta dos corpos ainda é prática econômica." (idib., p. 37) E, portanto, uma política feminista molecular ainda não poderá prescindir da ocupação dos estratos; ainda não poderá prescindir de operar a história a partir da categoria mulher para subtraí-la e desencadear devires minoritários. 


\section{Uma história das mulheres de menos}

Um manifesto de menos poderia nos ajudar? Penso que sim. Nesse texto, Deleuze analisa o teatro de Carmelo Bene (DELEUZE, 2010, p. 25) e tem o trabalho de decantar daquilo que acontece com $\mathrm{CB}$ entre texto e palco, uma tal operação que nos valeria o tempo de estudar. A dita operação, narrada em tom muito elogioso, se trata de uma minoração. O processo todo seria mesmo uma operação matemática com sentido à subtração. Trata-se de impor um tratamento de minoração para liberar devires contra a História.

Mas gostaria, aqui, de ler também: "Por [esta] operação deve-se entender o movimento da subtração, da amputação, mas já recoberto por um outro movimento, que faz nascer e proliferar algo de inesperado, como numa prótese (...)" (ibid., p. 29) Sobre a peça de Carmelo Bene, Deleuze diz ainda que esta "acaba com a constituição do personagem, ela só tem como objeto o processo dessa constituição, e não se estende nada para além dele. Ela para com o nascimento, enquanto habitualmente é na morte que se para.” (ibid., p. 31) Assim também contar a história da mulher que deviemos para, logo assim, dar a ela um fim.

\section{Considerações finais}

Há algo que precede o devir, há algo que sucede a história. Há como uma zona limiar; há algo entre, no meio, uma vizinhança comum. Pegamos emprestadas as fórmulas das línguas maior e menor - que aparecem no Platô 4 - para arriscar dizer que não existem dois tipos de mulher, a da história e a do devir, mas dois tratamentos possíveis de uma mesma. Ora tratam-se suas variáveis de maneira a extrair delas constantes; ora, de maneira a colocá-las em estado de variação contínua. Federici, como autora, trata as variáveis históricas antes dispersas a partir de um enxerto, uma prótese: mulheres. Desta operação, extrai uma constante. O corpo feminino como sítio matricial do capitalismo, ou como máquina de fazer proletários. No entanto, as bruxas como autoras da história fazem variar a história oficial, fazem dúbios os fatos, fazem-nos facticius, feitiço. E, pois bem, o menor intervalo, a variação contínua, é sempre diabólico: a bruxa das metamorfoses se opõe ao rei hierático. (DELEUZE; GUATTARI, 2011, p. 61) A operação seria esta: conquistar a história maior para nela traçar linhas menores ainda desconhecidas.

E é na voz de Silvia que ouvimos que "em primeiro lugar, havia um desejo de repensar o desenvolvimento do capitalismo a partir de um ponto de vista feminista, ao mesmo tempo evitando as limitações de uma 'história das mulheres' separada do setor masculino na classe trabalhadora." (FEDERICI, 2017, p. 23) e "O que podemos aprender sobre o desdobramento capitalista, passado e presente, quando examinado sob perspectiva feminista?”, nos pergunta ainda a autora. (ibid., p. 25) Em resposta, nós: há uma operação de enxerto presente em Calibã e a bruxa. E, no entanto, só na medida em que há também uma subtração em curso, pois enxertase uma prótese, uma personagem.

Bem, sugeridos por estas leituras que fizemos, suporíamos que os limites de uma história são sempre evidenciados por aquilo que traz ruídos, aquilo que sobra, que a excede. Os limites da história estariam, portanto, precisamente neste ponto onde o que é próprio dela já não é suficiente e onde as diferenças rasgam os corpos que acabamos de montar: urgindo variações necessárias. Aí, neste limite, há pelo menos uma escolha política a ser feita. Porque os limites da história se encontram na fronteira com aquilo que já é comum, naquilo que já não é mais particular. História, aí em seu limite, suscita um devir: tomar parte no comum, distanciar-se de nossas formas históricas e mover-se a esta zona imprecisa, confusa, diabólica. Devir é um problema político.

Federici diz que a história da caça às bruxas é uma história do presente. E, aqui, já poderemos dizer: recontar a história da caça às mulheres é uma história contra o presente. Pois 
que, esta pista, encontramos em um texto de Deleuze para Daniel Defert em 84 dedicado aos principais conceitos de Michel Foucault - que, talvez não por coincidência, seja do autor de onde dissemos outrora partir. E, por Deleuze, ficamos sabendo que Foucault diz fazer "estudos de história" sem, no entanto, fazer um "trabalho de historiador". O que faz seria mesmo um trabalho de filósofo, mas que, é preciso ainda dizer, não é uma filosofia da história. Não haveria palavras melhores do que as do próprio Deleuze e o cito:

O que é histórico, são todas as formações estratificadas, feitas de estratos. Mas pensar [e aqui caberia a nós ler "pensar" por devir] é atingir uma matéria não estratificada, entre os frisos ou nos interstícios. Pensar [ou, ainda, devir] está numa relação essencial com a história, porém não é mais histórico do que eterno. Está mais próximo daquilo que Nietzsche chama de intempestivo: pensar o passado contra o presente - o que seria um lugar-comum, uma nostalgia, um retorno, caso não se acrescentasse: 'Em favor, assim o espero, de um tempo por vir' (DELEUZE, 2016, p. 257 - grifo meu).

Contra a indústria, somos corpo; contra o organismo, somos máquina. Se nos quiserem neutras, somos mulheres. Queiram-nos mulheres, seremos monstros. Feministas serão estas; serão monstros de corpo indiscernível, mas jamais amorfo, incalculável, mas jamais zerado, sanguinolentas, mas também sem filho, sem útero, sem ovário, com testículos, sem menstruação. Feministas é o nome que escolhemos nos dar pra fazer caber tanto as dores do que somos quanto as delícias do que desejamos ser - e, com rebeldia, já somos.

Contra a anatomia, somos histéricas. Contra a histeria, fazemos história.

\section{Referências}

BEAUVOIR, Simone. Le deuxiéme sexe 1. Paris: Éditions Gallimard, 1949.

BUTLER, Judith. Problemas de gênero. Rio de Janeiro: Civilização Brasileira, 2003.

DELEUZE, Gilles. Conversações (1972-1990). 3. ed. São Paulo: Ed. 34, 2013.

DELEUZE, Gilles. Dois regimes de loucos: textos e entrevistas (1975-1995). São Paulo: Ed. 34, 2016.

DELEUZE, Gilles. Sobre o teatro: um manifesto de menos; o esgotado/ Gilles Deleuze. Rio de Janeiro: Zahar, 2010.

DELEUZE, Gilles; GUATTARI, Felix. Mil platôs: capitalismo e esquizofrenia, vol. 2. 2. ed. São Paulo: Ed. 34, 2011.

DELEUZE, Gilles; GUATTARI, Felix. Mil platôs: capitalismo e esquizofrenia, vol. 3. 2. ed. São Paulo: Ed. 34, 2012a.

DELEUZE, Gilles; GUATTARI, Felix. Mil platôs: capitalismo e esquizofrenia, vol. 4. 2. ed. São Paulo: Ed. 34, 2012 b.

FEDERICI, Silvia. Calibã e a bruxa: mulheres, corpo e acumulação primitiva. Trad. Coletivo Sycorax. São Paulo: Elefante, 2017. 
DA MULHER QUE DEVIEMOS ÀQUELAS QUE HÃO DE VIR: COMO RECONTAR A HISTÓRIA...

FEDERICI, Silvia. Witches, witch-hunting and women. 1. ed. Oakland: PM Press. 2018.

FOUCAULT, Michel. História da sexualidade I: a vontade de saber. São Paulo: Paz e Terra, 2017.

KEHL, Maria Rita. Maria Rita Kehl e Freud | Episódio 3. 2018. (7m17s). Disponível em: https://youtu.be/-HaBp0JiwMg.

MOZÈRE, Liane. Devenir-femme chez Deleuze et Guattari: quelques éléments de présentation. Cahiers du Genre, v. 38, n. 1, p. 43-62, 2005.

SARZEDA, Carolina. Caça aos corpos rebeldes: Federici e Foucault entre bruxas. 2019. Trabalho de conclusão de curso (Graduação em Psicologia) - Instituto de Psicologia, UFF, Niterói, 2019. 